$1-2018$

\title{
Consequences of drift and carcass decomposition for estimating sea turtle mortality hotspots
}

\author{
Bianca Santos \\ Virginia Institute of Marine Science \\ David M. Kaplan \\ Virginia Institute of Marine Science \\ Marjorie A.M. Friedrichs \\ Virginia Institute of Marine Science \\ Susan G. Barco \\ Virginia Aquarium \& Marine Science Center \\ Katherine L. Mansfield \\ University of Central Florida
}

See next page for additional authors

Follow this and additional works at: https://scholarworks.wm.edu/vimsarticles

Part of the Animal Sciences Commons, and the Environmental Monitoring Commons

\section{Recommended Citation}

Santos, Bianca; Kaplan, David M.; Friedrichs, Marjorie A.M.; Barco, Susan G.; Mansfield, Katherine L.; and Manning, James P., Consequences of drift and carcass decomposition for estimating sea turtle mortality hotspots (2018). Ecological Indicators, 84, 319-336.

10.1016/j.ecolind.2017.08.064

This Article is brought to you for free and open access by the Virginia Institute of Marine Science at W\&M ScholarWorks. It has been accepted for inclusion in VIMS Articles by an authorized administrator of W\&M ScholarWorks. For more information, please contact scholarworks@wm.edu. 


\section{Authors}

Bianca Santos, David M. Kaplan, Marjorie A.M. Friedrichs, Susan G. Barco, Katherine L. Mansfield, and James P. Manning 


\section{Consequences of drift and carcass}

2 decomposition for estimating sea turtle

3 mortality hotspots

5 Bianca S. Santos ${ }^{1 a^{*}}$, David M. Kaplan ${ }^{1 b}$, Marjorie A.M. Friedrichs ${ }^{1 c}$, Susan G. Barco ${ }^{2 d}$,

6 Katherine L. Mansfield ${ }^{3 e}$, James P. Manning ${ }^{4 f}$

7 1. Virginia Institute of Marine Science, College of William \& Mary, Gloucester Point, VA

$8 \quad 23062$

9 2. Virginia Aquarium \& Marine Science Center, Virginia Beach, VA 23451

10 3. University of Central Florida, Biology Department, Orlando, FL 32816

11 4. National Oceanic Atmospheric Administration, Northeast Fisheries Science Center, Woods

$12 \quad$ Hole, MA 02543

13 Author email addresses: (a) bsantos@vims.edu; (b) dmk@vims.edu; (c) marjy@vims.edu; (d)

14 sgbarco@virginiaaquarium.com; (e) kate.mansfield@ucf.edu; (f) james.manning@noaa.gov

15 * Corresponding author: bsantos@vims.edu; Phone: 1-804-684-7986

18 Running title: Drift and decomposition of sea turtles

19 Abstract word count: 305

20 Main text word count (from Introduction to end of Discussion): 7832

21 Figures: 8

22 Tables: 7 
24 Sea turtle strandings provide important mortality information, yet knowledge of turtle carcass at-

25 sea drift and decomposition characteristics are needed to better understand and manage where

26 these mortalities occur. We used empirical sea turtle carcass decomposition and drift

27 experiments in the Chesapeake Bay, Virginia, USA to estimate probable carcass oceanic drift

28 times and quantify the impact of direct wind forcing on carcass drift. Based on the time period

29 during which free-floating turtle carcasses tethered nearshore were buoyant, we determined that

30 oceanic drift duration of turtle carcasses was highly dependent on water temperature and varied

31 from 2-15 days during typical late spring to early fall Bay water conditions. The importance of

32 direct wind forcing for turtle carcass drift was assessed based on track divergence rates from

33 multiple simultaneous deployments of three types of surface drifters: bucket drifters, artificial

34 turtles and turtle carcass drifters. Turtle drift along-wind leeway was found to vary from 1-4\% of

35 wind speed, representing an added drift velocity of approximately 0.03-0.1 m/s for typical Bay

36 wind conditions. This is comparable to current speeds in the Bay $(0.1-0.2 \mathrm{~m} / \mathrm{s})$, suggesting wind

37 is important for carcass drift. Estimated carcass drift parameters were integrated into a

38 Chesapeake Bay oceanographic drift model to predict carcass drift to terrestrial stranding

39 locations. Increased drift duration (e.g., due to low temperatures) increases mean distance

40 between expected mortality events and stranding locations, as well as decreases overall

41 likelihood of retention in the Bay. Probable mortality hotspots for the peak month of strandings

42 (June) were identified off coastal southeastern Virginia and within the lower Bay, including the

43 Bay mouth and lower James River. Overall, results support that sea turtle drift time is quite

44 variable, and varies greatly depending on water and air temperature as well as oceanic 
45 conditions. Knowledge of these parameters will improve our ability to interpret stranding events

46 around the globe.

47 Key Words

48 sea turtle strandings; sea turtle mortality; Chesapeake Bay; carcass decomposition; drift leeway;

49 drift simulations; endangered species; conservation 


\section{Introduction}

51 Coastal strandings of deceased sea turtles provide a unique opportunity to study drivers

52 of mortality in the world's threatened and endangered sea turtle populations (Epperly et al. 1996,

53 Hart et al. 2006). However, interpreting coastal strandings of dead sea turtles can be challenging

54 for a number of reasons. Level of turtle carcass decomposition and/or lack of visible injuries

55 often make determining the cause of mortality impossible. Furthermore, although stranding

56 events provide a general time period and region of mortality, they do not provide a specific

57 space-time location for mortality events that can be directly related to potential causal factors

58 (e.g., human activities, environmental conditions, etc.). Management guidelines have highlighted

59 the need to better understand landfall patterns of stranded sea turtles to infer possible causes of

60 mortality from mortality locations (Turtle Expert Working Group 1998).

61 Sea turtle carcasses typically sink upon death, until the accumulation of decomposition

62 gases causes the body to bloat and float to the surface (Epperly et al. 1996). At this point, the

63 body is partially submerged and acts as a drifting object. The drift of a deceased sea turtle from

64 death at-sea to a terrestrial stranding location depends on physical forces, namely the direction

65 and intensity of local currents and winds (Epperly et al. 1996, Hart et al. 2006). Forecast models

66 integrating these physical forcing mechanisms can be used to predict the trajectories of drifting

67 objects, including deceased sea turtles. However, the drift characteristics of turtle carcasses, such

68 as the impact of direct wind forcing on carcass movements and the period of time carcasses are

69 positively buoyant and, therefore, capable of significant horizontal movements at the ocean

70 surface, are poorly understood. Careful interpretation of stranding observations based on detailed

71 knowledge of these carcass drift parameters is necessary to better identify probable space-time

72 coordinates of mortality events. 
The Chesapeake Bay (Bay) and its surrounding coastal waters are critical forging and

74 developmental habitat for the approximately 5,000 to 20,000 sea turtles (primarily juveniles)

75 who use Bay waters seasonally (Musick and Limpus 1997, Coles 1999, Mansfield et al. 2009).

76 However, a significant number of sea turtle strandings are recorded on local beaches each year.

77 Approximately 100 to 300 sea turtles are found stranded on Virginia’s coastline, of which the

78 vast majority are deceased (Mansfield 2006, Swingle et al. 2016). Despite a number of

79 management efforts aimed at reducing turtle mortality, hundreds of turtles continue to wash up

80 every year (National Marine Fisheries Service 2006, Dealteris and Silva 2007, Swingle et al.

81 2016). Furthermore, as most fatalities potentially go unobserved due to low likelihood of landfall

82 and carcass decomposition, these stranding events may considerably underestimate total at-sea

83 mortality (Murphy and Hopkins-Murphy 1989, Epperly et al. 1996). With all sea turtles within

84 U.S. waters classified as threatened or endangered (National Research Council 1990), there is a

85 pressing need to understand stranding events and identify sources of mortality to ensure

86 population recovery.

$87 \quad$ Here we address two key uncertainties when estimating mortality locations using

88 stranding data and oceanographic drift simulations: (1) the probable amount of time dead turtles

89 drift before stranding on shore, and (2) the correction to pure oceanic drift needed to account for

90 direct wind forcing on turtle carcasses floating at the surface. A critical factor influencing

91 oceanic drift times is the decomposition rate of carcasses, which controls both how long the

92 carcass will remain buoyant and what decomposition state it will be in when it strands. Carcass

93 decomposition studies are needed to relate the level of decomposition of observed stranded

94 turtles to probable water drift times; however, very limited research on carcass decomposition

95 has been conducted on sea turtles. Higgins et al. (1995) observed the complete decay of two 
96 Kemp's ridleys to occur within 4-12 days; however, one turtle yielded unreliable results due to

97 inconsistencies in sampling protocol between treatments. Furthermore, this study's subtropical

98 location in the Gulf of Mexico may not be representative of the more temperate conditions in our

99 region, the Chesapeake Bay. Intermittent observations noted in Bellmund et al. (1987) of five

100 dead turtles entangled in a pound net in the Chesapeake Bay suggests total decay to occur on a

101 much longer time scale, upwards of 5 weeks, yet detailed information on oceanographic

102 conditions, time of year, or turtle sizes are not presented in the study. The discrepancies in

103 decomposition results, limited ocean temperature range, and small sample sizes highlight the

104 need for controlled field studies relating carcass condition to probable drift time over a range of

105 environmental conditions.

106 In addition, whereas ocean circulation models are often available to assess the impact of

107 currents, little is known about the impact of direct wind forcing on the surface transport of turtle

108 carcasses. An object's movement through water caused by surface winds is referred to as it's

109 leeway (Allen and Plourde 1999, Breivik et al. 2011). The impact of winds on drifting objects is

110 generally assessed in terms of leeway coefficients representing the fraction of the wind speed

111 that must be added to the along-wind and cross-wind current components to accurately simulate

112 drift patterns (Allen 2005). Field experiments to determine leeway coefficients have been carried

113 out to assess drift characteristics of a variety of objects, such as watercrafts and human bodies,

114 primarily for the purposes of search and rescue operations (Allen and Plourde 1999, Breivik et

115 al. 2011). Some studies have investigated the drift of animal carcasses in relation to likelihood of

116 carcass landfall (Degange et al. 1994), but few provide specific estimates of carcass leeway

117 parameters (Bibby and Lloyd 1977, Bibby 1981). Nero et al. (2013) evaluated turtle carcass

118 leeway from the track of a single tagged moribund turtle, providing the sole estimate of sea turtle 
119 wind-induced drift in the literature. There is a noted need to combine experimentally obtained

120 drifter data with oceanographic models to better understand how oceanic conditions affect the

121 flow of carcasses at sea (Hart et al. 2006, Nero et al. 2013, Koch et al. 2013). To address this

122 data gap, we carried out field drift experiments to better estimate the impact of winds on turtle

123 carcass drift patterns (specifically, the along-wind and cross-wind leeway coefficients).

124 Results from both the decomposition study and the carcass drift experiments were used to 125 parametrize a carcass drift model and provide initial estimates of probable mortality locations

126 from deceased sea turtle strandings data for coastal areas in the Chesapeake Bay. Collectively,

127 the outcomes of this study enhances our ability to infer locations of mortality from stranding 128 events in the Bay, as well as elsewhere around the globe.

129 2. Materials and Methods

130 For simplicity in this study, we will use the term "stranding" to refer to the final beached

131 location of a deceased sea turtle. Though stranding datasets often also include data on sick or

132 injured sea turtles that are alive, simulation of the movements of these individuals is greatly 133 complicated by their potential for active swimming, and, therefore, we focus exclusively on 134 deceased individuals.

\subsection{Decomposition study}

136 When stranded turtles are found on the beach (which generally occurs within 12 hours of 137 stranding in populated areas), carcass condition is assessed on a condition code scale from 1 138 (freshly deceased; we are excluding alive code 0 strandings) to 5 (bones) as per the National 139 Oceanographic and Atmospheric Administration’s Sea Turtle Stranding Salvage Network 140 (STSSN) stranding report forms and guidelines 
141 (http://www.sefsc.noaa.gov/species/turtles/strandings.htm) (Table 1). We conducted carcass

142 decomposition experiments to relate condition codes to probable post-mortem in-water times for

143 a variety of environmental conditions. The decomposition rate of eight juvenile sea turtles,

144 including two loggerheads (Caretta caretta), two Kemp’s ridleys (Lepidochelys kempii) and four

145 greens (Chelonia mydas), ranging in size from 26.3 to $68.0 \mathrm{~cm}$ straight carapace length notch to

146 tip and 2.38 to $36.5 \mathrm{~kg}$ in mass, were assessed during the summers of 2015 and 2016. Carcasses

147 were supplied by the Virginia Aquarium \& Marine Science Center Stranding Response Program

148 (VAQS) and Maryland's Department of Natural Resources Marine Mammal and Sea Turtle

149 Stranding Program. Death was attributed to cold-stunning in all cases but one, where lacerations

150 on the carapace of a Kemp's ridley suggested death by vessel strike. All carcasses were assessed

151 with an initial condition code of 1 or 2 . Carcasses were frozen prior to use and thawed in a fresh

152 water bath before placement at the study site. Preliminary morphometric measurements were

153 recorded using standard measurement protocols (Wyneken 2001).

154 A moored buoy system was constructed that allowed for free movement of the carcass

155 throughout the water column and tethered in an area of 3 to $6 \mathrm{ft}$ of water varying with tide in the

156 York River, VA (Figure 1A). A 4-ft helix mooring anchor was installed into the bottom sediment

157 and attached to a bullet buoy with rope. The turtle carcass was wrapped in 4-inch heavy duty

158 polyethylene plastic mesh held together by carabiners and attached to the mooring system using

159 a rope and carabiner (Figure 2). This allowed the carcass to freely move through the water

160 column as its buoyancy changed due to decomposition processes over time. For two trials, a

161 GoPro HERO3+ camera was attached to PVC-pipe embedded in the plastic mesh, and 3-hours of

162 5-second time lapse photos were recorded daily. The GoPro and PVC-pipe apparatus were

163 adjusted to achieve neutral buoyancy so as not to impede the carcass from floating and sinking. 
165 anchor line and brought to shore where it was thoroughly photographed and qualitatively

166 analyzed, including a detailed description of the carcass decomposition state, its associated

167 condition code and whether it was at the surface or bottom of the water column at the time

168 (Figure A1). As many of the codes are quite broad and can include a wide range of

169 characteristics, early and late categories for each condition code criteria were also recorded.

170 Code 4 is characterized as “dried carcass” by STSSN guidelines, but the turtle carcasses in this

171 study were submerged for the entire trial and did not exhibit this type of desiccation, thus, code 4

172 was not observed. Temperature data were obtained from the Virginia Estuarine and Coastal

173 Observing System Gloucester Point continuous water quality monitoring station at Gloucester

174 Point, VA (http://web2.vims.edu/vecos/Default.aspx), located within 150 meters from the

175 experimental study site. Linear regression models were performed to assess the effect of

176 temperature on duration of positive buoyancy and total time to decay to code 5. Due to low

177 sample size and lack of sufficient replicates across species and size classes, the effect of turtle

178 species or size on decomposition could not be assessed, but we did not observe any obvious,

179 large differences in decomposition between individuals of different sizes or species were

180 observed.

1812.2 Drift study

182 To assess the effect of wind forcing on turtle drift, three types of drifters were used: turtle

183 carcass drifters, bucket drifters and wood-foam turtle drifters (Figure 3; Table 2). Turtle carcass

184 drifters were constructed from the remains of deceased stranded turtles collected by VAQS

185 (Figure 3A). Prior to use, the turtle plastron and carapace were separated during necropsy (with

186 head and flippers still attached) and internal organs were removed. The body cavity was then 
187 filled with insulating foam sealant spray and holes were drilled around the perimeter of the

188 plastron and carapace pieces, which were reattached with heavy-duty zip ties and a thin $1.5 \mathrm{~cm} \mathrm{x}$

$1891.5 \mathrm{~cm}$ galvanized wire mesh on the underside of the carcass (Figure A2). The amount of foam

190 was based on the size of the body cavity and the need to maintain positive buoyancy. When the

191 turtle carcass drifter was floating, the majority of the shell was fully exposed with the apex of the

192 carcass edge forming the waterline, consistent with the floating behavior of a fully bloated turtle

193 carcass. A satellite-transmitting GPS receiver (Assetlink TrackPack transmitters) was mounted

194 on a self-righting crab pot buoy that was attached to the turtle via a rope passing through its

195 carapace (Figure A3). Although the impact of the buoy itself on carcass drift was not quantified,

196 it was made as small as possible and separated from the carcass to minimize impact. The

197 carcasses were stored prior to use in a freezer and were frozen at time of release.

198 The "bucket drifters" used in this study were very-near surface "Kathleen” drifters made

199 from inverted 5-gallon plastic buckets with weights and floats inside so as to be mostly

200 submerged when in water (Chen et al. 2009, Putman and Mansfield 2015) (Figure 3B;

201 http://www.nefsc.noaa.gov/epd/ocean/MainPage/lob/driftdesign.html). These were designed to

202 track near surface currents with movements relatively unaffected by wind. Of all the drifters

203 launched, the buckets most closely represent the movements of water particles, thus providing an

204 estimate of the near-surface current field to be compared with movements of the other two drifter 205 types.

206 The wood-foam turtle drifters were constructed out of layers of wood and polystyrene 207 foam in the approximate form of a juvenile loggerhead sea turtle (Figure 3C). These drifters 208 were included as a potential (more readily available) alternative to true turtle carcass drifters, 209 although it is worthwhile to note that the aspect ratio of the wood-foam drifter was a bit higher 
210 than the turtle carcass drifters (e.g. whereas the difference between straight carapace length and

211 curved carapace length for the carcass drifters ranged 5.2-7.8 cm, wood-foam drifters had a

212 difference of $14.9 \mathrm{~cm}$; Table 2). Additionally, the vertical profile of the wood-form turtle

213 included steps whereas the profile of a true turtle carcass is rounded. Both bucket drifters and

214 wood-foam turtle drifters were painted orange and small orange construction flags were attached

215 on top to make the drifters more visible to boaters.

216 We conducted four drifter releases in the main stem of the lower Chesapeake Bay during

217 the summer of 2016 (Figure 1A; Table 3). Each deployment included two bucket drifters and two

218 wood-foam turtle drifters. Due to the limited number of turtle carcasses available for this study,

219 only three loggerhead turtle carcasses were used in total. The first trial included two different

220 carcasses, while the others used a third carcass, which was collected within 24 hours of beaching,

221 refrozen, and redeployed for subsequent deployments. Given the large size of this third turtle

222 carcass drifter, short deployment periods, and good initial carcass state, the multiple freeze-thaw

223 cycles did not appear to compromise the head or flippers, all of which remained attached and

224 essentially intact until the turtle was disposed of after the final deployment. The drifters were

225 released by boat in the middle of the lower Chesapeake Bay and GPS locations were obtained

226 every 30-minutes via satellite. Drifter positions were closely monitored until the objects beached, 227 typically within 1-3 days.

228 Locations for all drifter types were matched in time by linearly interpolating between

229 positions where necessary. Meteorological data (i.e., wind speed and direction) available in 6-

230 minute intervals were obtained from the National Oceanographic and Atmospheric

231 Administration's Center for Operational Oceanographic Products and Services

232 (http://tidesandcurrents.noaa.gov/) monitoring station 8637611 York River East Rear Range 
233 Light. Due to the presence of a weather front in the area during the second deployment,

234 meteorological data for this trial were instead obtained from the 8638614 Willoughby

235 Degaussing Station located in an adjacent tributary (Figures A4-A7). Wind speed was adjusted

236 from 57 feet recorded height to the standard $10 \mathrm{~m}$ reference height using the methods described

237 in Hsu et al. (1994). East-west (u) and north-south (v) wind vector components were computed

238 and wind vector components were averaged over 30-minute intervals corresponding to the drifter

239 data time series.

240 Drift leeway of the wood-foam drifters and turtle carcass drifters were computed based

241 on the observed motion of the drifters relative to bucket drifters (most closely representing the

242 surface current field). Leeway can be measured using a direct or indirect approach (Allen and

243 Plourde 1999, Breivik et al. 2011). Here, drift leeway was measured indirectly by comparing the

244 movements of the turtle and wood-foam drifters to those of the bucket drifters. The rate of

245 change in the separation between drifters were calculated at pairs of consecutive time steps.

246 Linear-regression analysis was used to derive leeway coefficients based on the slopes of the

247 regression line between wind speed and along-wind leeway, cross-wind leeway or leeway speed.

248 In addition, separation distances as a function of time since release were calculated between each

249 combination of drifter pairs.

250 Due to the separation of drifters over time, movements were most comparable during the

251 initial hours following deployment when objects were close together and likely experiencing the

252 same physical oceanographic forces. Thus, the duration of each trial was limited from time of

253 deployment to the next slack tide, when the tidal flow reversed direction and currents were weak

254 and spatially incoherent (Hospital et al. 2015). This time period ranged from 2.5-8.5 hours based

255 on deployment. Slack tide data were obtained from the National Oceanographic and 
257 station ACT5406 York River Entrance Channel (NW end).

258 Linear regression models used to estimate leeway coefficients for the turtle carcass

259 drifters and wood-foam drifters included categorical variables for each deployment, (i.e. drifter

260 release trial), turtle carcass drifter or wood-foam drifter, and the bucket being compared with a

261 given carcass or wood-foam drifter trajectory. When estimating wood-foam drifter leeway, both

262 bucket and wood-foam drifter were considered random nested effects inside wind speed and

263 deployment. When estimating turtle carcass drifter leeway, bucket was a random effect nested

264 inside wind speed, deployment and carcass drifter. The regression model included effects of

265 categorical variables on both the intercept and slope of the relationship between wind speed and

266 leeway. Analysis of variance was used to test for differences in wind leeway with deployment or

267 individual carcass drifter.

268 Simple linear models including only wind speed as a predictor of leeway (values for

269 which were averaged across buckets) were also run to calculate leeway coefficients for each

270 deployment and turtle carcass drifter or wood-foam drifter combination. Both unconstrained (i.e.,

271 with a freely varying $y$-intercept) and constrained (i.e., $y$-intercept $=0$ ) linear regressions were

272 performed. Note that p-values for constrained regression estimates are not reported because level

273 of significance is unreliable when forcing the slope through zero.

$274 \quad 2.3$ Particle modeling

275 Estimated model parameters attained from the decomposition and drifter studies (i.e.,

276 likely drift duration from mortality location to stranding and along-wind leeway coefficient)

277 were integrated into an oceanographic drift model simulating carcass drift trajectories in the

278 Chesapeake Bay to observed stranding times and locations. The basic simulation strategy was to 
279 “release” many surface pseudo-particles (i.e., simulated particles) throughout the domain of the 280 oceanographic model, track these for a period of time based on wind and current estimates from 281 atmospheric and ocean circulation models, and identify those pseudo-particles that arrived at 282 stranding zones for each month. The initial release points for many such "stranding” forward 283 drift trajectories were then aggregated to estimate a probability distribution for the mortality 284 locations of stranded turtles for June, the peak month for strandings. No additional randomness 285 was added to the model to account for sub-grid-scale variability as the oceanographic and 286 atmospheric models themselves have errors and uncertainties that would be difficult to quantify 287 separately from sub-grid-scale variability. Using ocean circulation data from a Regional Ocean Modeling System (ROMS; version 289 3.6) physical oceanographic model of the Chesapeake Bay area (ChesROMS; Feng et al. 2015), 290 particles were released throughout the Bay and run forward in time using the offline Lagrangian 291 drift simulation tool Ichthyop version 3.1 (Lett et al. 2008). Simulations were conducted for the 292 time period 2001-2005 as ChesROMS ocean currents simulation data were only available for this 293 period at the time of this study. Computer simulations were configured to release 1,000 particles 294 randomly throughout the Bay every 6-hours with particle tracking time ranging from 2-8 days 295 based on results from the decomposition study. Based on observed variability in along-wind 296 leeway results from the drifter experiment, leeway ranging from 0-4\% of wind speed were added 297 to ChesROMS currents so that pseudo-particle trajectories represent the combined effects of 298 currents and direct wind forcing on surface transport. Wind forcing was derived from the North 299 American Regional Reanalysis (NARR) dataset (Mesinger et al. 2006). ChesROMS, NARR and 300 Ichthyop internal timesteps were all 3 hours. NARR winds were unavailable for 2016 at the time 301 of the study, and thus we were unable to use them for analyses in the drifter experiments. 
303 during 2001-2005 were analyzed to identify areas with high numbers of strandings. The years

304 2001-2005 was chosen to be consistent with simulations, but using a longer time period does not

305 change the regions identified as having a high stranding rate. Target zones were created in

306 sections of Accomack, Hampton, Norfolk, Northampton and Virginia Beach Counties (Figure

307 1A). Each zone has a 3-km offshore extent. Computer simulations were run targeting these

308 specific stranding-hotspots. Simulation results for relative particle density of the origins of

309 particles reaching target zones were mapped on a $5 \mathrm{~km} \times 5 \mathrm{~km}$ square grid.

3103. Results

\subsection{Decomposition study}

312 Initial assessments of all turtle carcasses indicated that the bodies were in good condition

313 with no significant marks or lesions, with the exception of one vessel-strike turtle carcass (turtle

314 3). The three lacerations on the vessel strike turtle did not seem to have severally altered

315 decomposition as results for this turtle carcass were consistent with those for the other carcasses.

316 A summary of condition code criteria used to evaluate the carcasses can be found in Table 1 and

317 preliminary measurements of all turtle carcasses used in the study is noted in Table 4 . The

318 majority of the turtles were a code 1 upon placement at the York River study site and sank

319 immediately. Positive buoyancy due to the accumulation of decomposition gases occurred within

320 the first two days in all carcasses. At time of surfacing, all turtle carcasses were observed with

321 some degree of bloating and assessed with a condition code of 2. Turtles 2 and 8 began as an

322 early code 2 and did not sink upon initial placement, but remained floating at the water surface. 
The effect of temperature was found to be statistically significant on both the duration of

324 positive buoyancy $\left(\mathrm{p}<0.001, \mathrm{R}^{2}=0.8605\right)$ and time to reach total decay (code 5$)\left(\mathrm{p}<0.001, \mathrm{R}^{2}=\right.$

325 0.8401) (Figure 4A). Duration of positive buoyancy ranged from 2-15 days. By a late code 3, all

326 turtle carcasses deteriorated to a point that the body was no longer intact enough to retain

327 decomposition gases, causing the bodies to sink and remain at the bottom of the sea floor until

328 reaching code 5. Duration of complete decomposition to code 5 ranged from 5-18 days (Figure

$3294 \mathrm{~B}$, Table 5). The eighth turtle, submerged in cooler water temperatures averaging $17^{\circ} \mathrm{C}$, did not

330 exhibit the same level of tissue disintegration as observed in the warmer water decomposition

331 trials (with average water temperatures of $20-29^{\circ} \mathrm{C}$ ). The remains from this turtle formed a mass

332 of tissue by day 18, when the turtle reached an early code 5 . Nearly all of the bones were

333 detached from the undistinguishable mass of fat by day 20, yet the tissue remnants were

334 observed to persist until day 23, when all remains were lost through the mesh.

335 Occasional observations were made of organisms scavenging within the body cavity of

336 the turtle carcasses during sampling, including juvenile blue crabs (Callinectes sapidus) and mud

337 snails (Nassarius spp.) In addition, a Go-Pro camera attached to the decomposition set up of two

338 trials (turtles 3 and 4) depicted the presence of a school of fish (Menidia menidia) feeding on the 339 plastron-side of turtle 3 while it was floating at the surface.

\section{$340 \quad 3.2$ Drift study}

341 Wind speed, deployment and individual turtle carcass drifter were found to have a

342 significant effect on along-wind leeway $(\mathrm{p}>0.05)$. Therefore, we conducted separate regressions

343 for each deployment-turtle combination. Unconstrained regressions indicated that along-wind

344 leeway was significantly related to wind speed for turtle carcass drifters 1 and 2, turtle carcass

345 drifter 3 during deployment 3, and wood-foam drifters during deployments 1 and 3-4. Cross- 
wind leeway was not found to be significant for any turtle carcass drifter, but was significant for

347 most of the wood-foam drifter deployments (Figure 5; Table 6). The 95\% confidence interval of

348 the slope for all components of leeway were largest in deployment 1 for both the turtle carcass

349 drifters and wood-foam drifters, which was also the deployment trial of the longest duration.

Along-wind leeway coefficients from a constrained (i.e. $y$-intercept $=0$ ) linear regression

351 ranged from $1.14-3.59 \%$ of wind speed, in wind conditions ranging from $0.08-4.24 \mathrm{~m} / \mathrm{s}$. At an

352 average wind speed of $2.85 \mathrm{~m} / \mathrm{s}$, this equates to a change in carcass movements of $0.03-0.1 \mathrm{~m} / \mathrm{s}$

353 due to the influence of wind versus currents alone. The along-wind leeway of the wooden turtles

354 ranged from $0.73-3.54 \%$ of wind, equating to approximately a $0.02-0.1 \mathrm{~m} / \mathrm{s}$ change in movement.

355 Along-wind leeway coefficients for turtle carcass drifters and wood-foam drifters were positively

356 correlated, but this correlation was not statistically different from zero (Pearson’s correlation

357 coefficient $=0.73, \mathrm{p}=0.17$ for $\mathrm{n}=5)$.

358 Despite being released in nearby areas, the tracks of the drift objects varied significantly

359 across deployments (Figure 6). Upon release, drifters were noted to diverge by type fairly

360 quickly (<1 hour), but all continued to move in the same general direction following deployment

361 until the direction of tidal currents began to reverse. This trend is most clearly observed in the

362 drifter tracks during deployment 2, which was the shortest deployment with objects beaching

363 approximately 26 hours after release. The buckets in particular were noted to remain fairly close

364 to one another throughout the majority of the drift release trials, and were the last objects to

365 make landfall in nearly all of the deployments.

\section{$366 \quad 3.3$ Carcass drift simulations}

367 During 2001-2005, 1487 of the reported Virginia sea turtle strandings occurred within the 368 model domain. The vast majority of these strandings $(82 \%, n=1222)$ occurred in three coastal 
areas of three Virginia counties: Northampton, Virginia Beach, and Norfolk (Figure 1A).

370 Although stranding events took place throughout the spring and into the early fall, the majority

371 of strandings occurred during late spring (May-June) and summer (Lutcavage and Musick 1985,

372 Mansfield 2006, Barco and Swingle 2014), with nearly half of the standing events occurring

373 during June alone (44\%, n=660; Figure 1B).

The spatial distribution of location of mortality to these three top stranding zones were

375 predicted using computer simulations applying a variety of parameter estimates covering the

376 range of values identified in the drifter and decomposition studies. Along-wind leeway

377 coefficients of $0 \%, 2 \%$ and $4 \%$ of wind speed were examined. Water temperatures in the lower

378 Chesapeake Bay during peak times of late spring and summer strandings typically average

379 around $20-30^{\circ} \mathrm{C}$, thus drift durations of 2, 5 and 8 days were examined. Summaries of release

380 points of particles that land in the three top zones where Virginia strandings occur during the

381 month of June suggest that most mortalities likely originate from areas within the lower Bay,

382 including the waters near the entrance to the Bay and the James River, as well as coastal waters

383 off of Virginia Beach county (Figures 7 and 8). An increase in drift duration was noted to

384 increase the distance of particle origin from the zone in all cases but one (4\% leeway for zone 2

385 for 8 days) (Table 7). Increasing the percentage of winds consistently increased distance of

386 particle origin from the zone for 2 days drift, but results were mixed for longer drift periods. In

387 addition, the total number of particles making landfall increased with increasing wind forcing

388 values across all zones, regardless of drift duration. For example, there was at least a 50\%

389 increase in the absolute number of particles reaching Zone 1 in simulations with a wind forcing

390 value of $4 \%$ versus $0 \%$ for all drift duration values (Figure A8). 
In the lower Chesapeake Bay, prevailing winds exhibit seasonal variability, with winds

392 prevailing from the southwest during the summer months (Paraso and Valle-Levinson 1996).

393 Summertime probability maps of particle origins reflect these dominant wind patterns, with a

394 notable shift towards a more eastern origin with the addition of stronger wind forcing, while a 395 north-south shift was less consistent (Figure A9).

\section{Discussion}

To our knowledge, our study provides the first use of extensive field experimentation to

398 better resolve key uncertainties when modeling dead turtle drift patterns, namely, water drift time

399 before stranding and the influence of direct wind forcing on turtle carcass drift trajectories.

400 Model simulations of top stranding zones throughout the Chesapeake Bay with different time

401 and wind forcing parameters highlight the sensitivity of drift patterns to parameter estimates.

402 This research is also the first efforts to use oceanographic modeling to identify potential areas of 403 turtle mortality in Virginia’s waters.

\section{4.1 Decomposition study}

The post-mortem interval is a key element in forensic investigations. All eight turtle

406 carcasses in this study decomposed to bones in less than 18 days, in water temperatures

407 averaging $17-29^{\circ} \mathrm{C}$. Higgins et al. (1995) observed the complete decay of two Kemp’s ridley

408 turtles from code 1 to code 5 in 4-12 days depending on water temperature, consistent with our

409 results. These results also fit well within the range of decomposition for other aquatic animals,

410 including an estimated drift duration for small cetaceans of 5-10 days depending on carcass state

411 (Peltier et al. 2012). 
413 stranding patterns. Only bloated, gas-filled carcasses with positive buoyancy can float and drift

414 large distances. Thus, the probability of a particular turtle carcass making landfall is directly

415 related to its buoyancy (Peltier et al. 2012). Water temperature plays a key role in the carcass

416 surfacing time of deceased marine animals (Parker 1970, Higgins et al. 1995, Patterson et al.

417 2007, Peltier et al. 2012). Decay processes are initiated predominately by the activity of

418 intestinal bacteria, which is accelerated in warmer conditions (Reisdorf et al. 2012). In this study,

419 time period to attain buoyancy ranged from less than 24-hours in warmer water temperatures

$420\left(28-29.5^{\circ} \mathrm{C}\right)$ to 2 -days in cooler waters $\left(17.5-20.5^{\circ} \mathrm{C}\right)$. Water pressure and depth can also

421 influence carcass surfacing time, and thus decomposition rates in the shallow waters of this study

422 may not be fully indicative of processes in deeper parts of the Bay. It is also worthwhile to note

423 that the carcasses in this study were frozen prior to use. Studies have shown that previously

424 frozen animals exhibit accelerated rates of disarticulation on land (Micozzi 1986), suggesting

425 that duration to achieve buoyancy might be greater for fresh dead turtles compared to the frozen

426 carcasses used in our study. Nonetheless, results match relatively well with Higgins et al. (1995),

427 where fresh dead turtle carcasses surfaced in less than 24 hours after placement in $33-34^{\circ} \mathrm{C}$

428 waters, and after $4-5$ days in $14-22^{\circ} \mathrm{C}$ waters. Sis and Landry (1992) observed red-eared pond

429 slider carcasses to resurface in less than two days after postmortem, and some cetacean carcasses

430 have been observed to inflate with gases within hours (Reisdorf et al. 2012). Although it is

431 possible that bottom currents may transport carcasses from initial site of mortality, low current

432 velocities in the bottom boundary layer, as well as contact with bottom sediments, likely lead to

433 submerged carcasses not moving far before achieving positive buoyancy. For example, net

434 displacement of a freshly deceased turtle prior to gaining buoyancy observed by Nero et al. 2013 
435 was approximately 1-km over a submergence period of 4.8 days. Finally, a stratified water

436 column with considerably lower temperatures at the bottom (e.g., as is typical of late spring) may

437 slow decomposition processes at the bottom and thus increase the amount of time before a

438 carcass surfaces beyond what was observed in our shallow water study.

439

Once a carcass surfaces, assuming it is not entangled, it will drift at the surface while

440 continuing to gradually decompose (Reisdorf et al. 2012). The carcass will eventually

441 decompose to a point where it is no longer intact enough to retain gases, and it will sink to the

442 bottom of the sea floor. Thus, drift duration of carcasses is limited to only the interval of positive

443 buoyancy, which varied with water temperature from 2 to 15 days in this study. In all trials, code

4443 was the stage at which the carcasses were not intact enough to retain gases, thereby sinking and

445 never reappearing again at the surface. These results are similar to those reported in Higgins et

446 al. (1995), and suggests that stranded sea turtles found on beaches must land prior to reaching a

447 late code 3 . For stranded turtles found in condition code 4 or 5, it is probable that this level of

448 decomposition occurred while on land or after reaching a shallow, nearshore environment.

449 Uncertainty in the time component surrounding sea turtle decomposition on land can be limited

450 by focusing on stranding events in highly populated areas, where beaches are frequently visited

451 and strandings are likely reported and documented in a timely fashion.

452 Our results indicate that water temperature plays a significant role on the duration of

453 surface drift time and thus on the probability of turtle carcasses making landfall. In particular, the

454 timing of the annual spring peak of turtle strandings observed in the Chesapeake Bay during May

455 and June may be partially explained by climatic conditions. Typically, sea turtles first begin

456 entering the Chesapeake Bay around mid-May when water temperatures approach $18-20^{\circ} \mathrm{C}$

457 (Mansfield 2006, Mansfield et al. 2009). Based on the results of this study, if mortality occurs at 
458 this time of the year when water temperatures are cooler, it is possible that turtles can drift for

459 upwards of 15 days after surfacing. However, as the summer progresses and water temperatures

460 rise, carcasses will likely decompose faster and thus drift for a much shorter time period (2-5

461 days). Therefore, increasing water temperature may decrease the likelihood of turtle carcasses

462 beaching. Due to faster decomposition in warmer waters, it is also likely that from late summer

463 to early fall only turtles that die close to shore will beach, as turtles dying further offshore will

464 decompose before washing ashore.

\section{$465 \quad 4.2$ Drift study}

466 Our leeway drift estimates of turtle carcass drifters are among the first attempts to

467 parameterize the drift characteristics of deceased sea turtles prior to stranding (but see Nero et al.

4682013 for another recent attempt). We found that turtle carcasses drift at approximately 1.14-

$4693.59 \%$ of the wind speed, equating to a change in movement of roughly $0.03-0.1 \mathrm{~m} / \mathrm{s}$ based on

470 typical Bay winds. With the typical currents in the Chesapeake Bay ranging from 0.1-0.2 m/s

471 (Guo and Valle-Levinson 2007), the effect of wind on turtle carcass drift is non-negligible and

472 must be considered when attempting to model drift trajectories.

473 Our use of constrained linear regressions (i.e., forcing the line of best fit to pass through

474 the origin) should provide a more accurate estimate of leeway than an unconstrained regression

475 assuming that objects remain at rest relative to surrounding waters in the absence of winds (Allen

476 2005, Breivik et al. 2011). It is also preferred over the unconstrained method when the range of

477 wind speed is limited (Breivik et al. 2011). Notably, winds during the second deployment, for

478 which relationships between along-wind leeway and wind speed were not significant, were the

479 weakest and smallest in range of all deployments (Tables 3 and 6). 
Our results of turtle drift between $1 \%$ and $4 \%$ of wind speed are similar to those reported

481 for other drifting animals. The drift speed of sea birds and dolphins has been estimated to range

482 between 2.5\% and 4\% of wind speed (Bibby and Lloyd 1977, Peltier et al. 2012), and Nero et al.

483 (2013) estimated the drift leeway of a Kemp’s ridley at 3.5\% of wind from comparing the track

484 of a satellite-tagged moribund turtle to simulated tracks from an ocean circulation model.

485 Although the high aspect ratio of the wood-foam drifters may have contributed to the somewhat

486 higher leeway values compared to the carcass drifters, the along-wind leeway for wood-foam

487 drifters was similar in magnitude to that of turtle carcass drifters, ranging from 0.73-3.54\%,

488 suggesting that these artificial drifters may provide a good proxy for true turtle carcasses.

Given the limited number of turtle carcasses that were available to use for the drifter

490 experiment, we cannot definitively say to what extent environmental variability between

491 deployments and/or physical differences between turtles explain variability in along-wind leeway

492 coefficient estimates. Nevertheless, there are suggestions in our data that both play a role. There

493 was a positive correlation between turtle carcass drifters and wood-foam drifter leeway

494 coefficients, suggestive of environmental differences between deployments being a source of

495 leeway variability (because the same wood-foam drifters were used for all deployments, but

496 carcasses differed between deployments). However, this correlation was not significantly

497 different from zero, indicating that more data are needed to confirm this effect. Turtle size also

498 appears to be related to leeway coefficient, but this effect is confounded with that of deployment,

499 complicating a definitive assessment. Estimated along-wind leeway for the largest turtle carcass

500 drifter (Carcass 2), which was used exclusively in the first deployment, was 3.59\%, whereas for

501 the smallest turtle carcass drifter (Carcass 3, used in deployments 2-4) it ranged from 1.14- 
$5021.44 \%$. This would suggest that larger carcasses are more heavily impacted by direct wind 503 forcing, but again more data is needed to confirm this.

504 One study limitation was the limited temporal extent of leeway data due to the fast 505 separation rate between the bucket drifters and the drift objects of interest. Here, we indirectly 506 measured the leeway of the turtle objects by tracking its drift relative to the movements of the 507 nearby bucket drifters, which were assumed to be representative of current conditions at the 508 location of the turtle carcass drifter. However, this method is only effective when drifting objects 509 are close together and in a relatively homogeneous current field, which typically only occurred 510 over the first phase of the tidal cycle after deployment (within 5-8 hours of release). The direct 511 method for estimating leeway coefficients, which uses a current meter attached directly to the

512 drift object of interest, is another approach that can improve accuracy of leeway estimates

513 (Breivik et al. 2011). In this study, the direct method was impractical due to the generally large 514 size of current meters and/or expense of implementation. If the drift object is too small to tow a 515 current meter, current data must be derived by some other means and thus the indirect method 516 must be used (Breivik et al. 2011).

517 Future investigations should also consider the ratio of the carcass drifter's above water to 518 below water cross sectional area. Percent exposure is important in measurements of leeway 519 (Isobe et al. 2011) and a better understanding of percent exposure of the carcass drifters is an 520 important avenue for additional research into leeway variability in turtle carcasses. Nevertheless, 521 the rough consistency of our results with the few other available leeway measurements in turtles 522 and other marine species suggests that our results are not a gross misrepresentation of reality. 


\subsection{Carcass drift simulations}

Probability maps for starting points of stranding pseudo-particles for the three zones with

525 the highest number of strandings in Virginia's waters during the peak stranding month of June

526 highlight areas of the lower Bay and coastal waters immediately south of the Bay mouth as

527 hotspots for turtle mortality in the region (Figure 8). Although the majority of area strandings

528 wash up on the lower bayside coast of Northampton County (Zone 1), our model suggests that

529 mortality for most of these turtles occur in waters spanning across the entire lower Chesapeake

530 Bay channel to the vicinity of the James River mouth. These lower Bay waters, particularly near

531 the entrance of the James, are also highlighted as a mortality hotspot for turtles washing up on

532 Norfolk and Virginia Beach coastlines (Zones 2 and 3), in addition to oceanic waters south of the

533 Bay mouth. Even for relatively long summer drift periods of 8 days, most stranding particles

534 originated within waters immediately east and west of the Bay mouth. The Chesapeake Bay and

535 Virginia’s coastal waters are subject to heavy commercial and recreational public use

536 (Terwilliger and Musick 1995), thus sea turtles in these areas are likely often subject to

537 interactions with human activities. Although cause of death for a vast number of Virginia

538 strandings cannot be determined from visual assessment or necropsies alone (Lutcavage and

539 Musick 1985), results of this study provide focus areas for further investigations of potential

540 causal mechanisms of mortality.

541 In addition, simulation results indicate the importance of physical processes and

542 decomposition rates for accurately estimating mortality locations. The mean location of particle

543 origin prior to beaching was noted to move further offshore as drift duration increased (Table 7),

544 consistent with studies that demonstrate a negative correlation between release distance and

545 carcass recovery (Hart et al. 2006). Importantly, this also highlights a probable bias in stranding 
546 records. Although simulation results depict the majority of turtles as dying relatively close to

547 stranding locations, this may not reveal a lack of turtle mortality further offshore, but rather that

548 dead turtles have a greater likelihood of making landfall if mortality occurs closer to shore and in

549 areas with high coastal retention (otherwise their bodies may simply be lost at sea). For example,

550 the area off the bayside coast of southern Northampton County (Zone 1) where the most

551 strandings and particle retention occurred is also the area of a cyclonic eddy system which has

552 been noted to entrain particles in other studies (Hood et al. 1999). The high number of strandings

553 observed in this area may be due to prevailing physical processes facilitating the entrainment of

554 carcasses, further highlighting the key role physical oceanographic processes play in determining

555 the likelihood that a sea turtle carcass strands. Improving representation of sub-grid-scale

556 variability in the carcass drift model could increase the spread of particles and represents a

557 possible improvement for future modeling studies.

558 Increasing the along-wind leeway coefficient used in the model had variable effects

559 (depending on duration of drift period) on the distance from the target zones and spatial spread of

560 probable points of origin for stranding particles. Nevertheless, increasing this parameter

561 consistently increased the number of particles making landfall for all target zones (Figure A8).

562 As currents move predominantly in an alongshore direction, the addition of winds allows for

563 cross-shore movement of simulated particles, facilitating deposition in coastal areas. These

564 trends were also reflected in the drift deployment experiments. The bucket drifters were the last

565 objects to make landfall in nearly all of the deployments, highlighting the essential need to

566 incorporate wind forcing effects in oceanographic simulations to properly represent drift of

567 deceased turtles. 
Although sea turtle strandings provide a unique opportunity to study turtle mortality,

570 these events often provide little insight on causes of mortality and likely only represent a fraction

571 of total mortality occurring at sea. Given the protected status of sea turtles, availability of turtle

572 carcasses for research to elucidate drift patterns of turtle carcasses is extremely limited. Despite

573 the limited sample size, our results provide the best estimate of turtle drift parameters currently

574 available, and therefore, have significant potential for future use in modeling simulations aimed

575 at interpreting stranding data. For example, the Sea Turtle Stranding and Salvage Network has

576 been monitoring and collecting data on turtle strandings in the United States since 1980. With a

577 dataset spanning several states and more than 30 years, this data potentially provides an

578 important opportunity to apply our model to strandings in other geographic regions. Hindcasts of

579 turtle carcass drift trajectories to final terrestrial stranding locations can be extremely useful in

580 interpreting stranding events, and accurate information on the drift characteristics of sea turtles

581 will result in more precise predictions of potential mortality locations.

582 This work is an important step for more robust analyses modeling the drift of stranded

583 sea turtles to Chesapeake Bay beaches. Furthermore, drift information obtained from this study

584 can be utilized in sea turtle carcass drift models to analyze strandings data from many other areas

585 of the world. Our results indicate that sea turtle drift time may be quite short at 2-15 day in

586 typical Bay spring-early fall conditions. We also determined that turtles drift at 1-4\% of wind

587 speed, demonstrating that direct wind forcing has a non-negligible role in determining drift

588 trajectories. Oceanographic simulations identify potential mortality hotspots for the peak month

589 of strandings (June) in waters of the lower Chesapeake Bay and oceanic areas off southern

590 Virginia, providing focus areas for future investigations into likely drivers of sea turtle mortality. 
591 These results are essential to improving our ability to predict mortality locations from stranding

592 events not only in the Chesapeake Bay, but around the globe, providing managers with essential 593 information to better protect vulnerable sea turtle populations worldwide. 
We would like to acknowledge the Virginia Aquarium \& Marine Science Center

596 Stranding Response Program and A. Weschler with the Maryland Department of Natural

597 Resources for providing the sea turtle carcasses used in this study. We would also like to thank J.

598 Gwartney-Green, S. Rollins, J. Snouck-Hurgronje, T. Armstrong, D. Jones, and K. Bemis for

599 assistance in the field and S. Rollins and D. Malmquist for providing photos. Funding for this

600 project was provided through the College of William and Mary's Green Fee Funding, the

601 Virginia Institute of Marine Science (VIMS), the VIMS GK-12 Sheldon H. Short Trust Program,

602 the Dominion Foundation and Virginia Sea Grant. This work was performed in part using

603 computational facilities at the College of William and Mary which were provided with the

604 assistance of the National Science Foundation, the Virginia Port Authority, Sun Microsystems,

605 and Virginia's Commonwealth Technology Research Fund. Mention of trade names is for

606 identification purposes only and does not imply endorsement the National Oceanic and

607 Atmospheric Administration nor any of its subagencies. We thank two anonymous reviewers for

608 their constructive and encouraging comments that greatly improved this manuscript. This is

609 contribution XXXX from the Virginia Institute of Marine Science.

610 


\section{Literature Cited}

612

613 Allen, A. 2005. Leeway Divergence. Technical Report No. CG-D-05-05, U.S. Coast Guard 614 Research and Development Center. Groton, CT.

615 Allen, A. A., and J. V. Plourde. 1999. Review of Leeway: Field Experiments and

616 Implementation. Technical Report No. CG-D-14-98, U.S. Coast Guard Research and Development Center. Groton, CT.

618 Barco, S., and W. M. Swingle. 2014. Sea Turtle Species in the Coastal Waters of Virginia:

619 Analysis of stranding and survey data. VAQF Scientific Report \#2014-07b, Virginia Aquarium \& Marine Science Center Foundation. Virginia Beach, VA.

621 Bellmund, S., J. A. Musick, R. Klinger, R. Byles, J. A. Keinath, and D. Barnard. 1987. Ecology of sea turtles in Virginia. Scientific Report No. 119, Virginia Institute of Marine Science.

Bibby, C. J. 1981. An Experiment on the Recovery of Dead Birds from the North Sea. Ornis Gloucester Point, VA.

626 Bibby, C. J., and C. S. Lloyd. 1977. Experiments to determine the fate of dead birds at sea. 627 Biological Conservation 12:295-309.

628 Breivik, O., A. A. Allen, C. Maisondieu, and J. C. Roth. 2011. Wind-induced drift of objects at sea: The leeway field method. Applied Ocean Research 33:100-109.

630 Chen, F., D. G. MacDonald, and R. D. Hetland. 2009. Lateral spreading of a near-field river plume: Observations and numerical simulations. Journal of Geophysical Research 114:C07013. 
633 Coles, W. C. 1999. Aspects of the Biology of Sea Turtles in the Mid-Atlantic Bight. PhD

634 Dissertation, Virginia Institute of Marine Science, College of William and Mary. 635 Gloucester Point, VA.

636 Dealteris, J., and R. Silva. 2007. Performance in 2004 and 2005 of an alternative leader design on the bycatch of sea turtles and the catch of finfish in Chesapeake Bay pound nets, offshore Kiptopeake, VA. National Marine Fisheries Service, New England Fisheries Science Center. Woods Hole, MA.

Degange, A. R., A. Doroff, and D. H. Monson. 1994. Experimental recovery of sea otter carcasses at Kodiak Island, Alaska, following the Exxon Valdez oil spill. Marine Mammal Science 10:492-496.

643 Epperly, S. P., J. Braun, A. J. Chester, F. A. Cross, J. V Merriner, P. A. Tester, and J. H. Churchill. 1996. Beach strandings as an indicator of at-sea mortality of sea turtles. Bulletin of Marine Science 59:289-297.

646 Feng, Y., M. A. M. Friedrichs, J. Wilkin, H. Tian, Q. Yang, E. E. Hofmann, J. D. Wiggert, and Journal of Geophysical Research: Biogeosciences 120:1666-1695.

650 Guo, X., and A. Valle-Levinson. 2007. Tidal effects on estuarine circulation and outflow plume 651 in the Chesapeake Bay. Continental Shelf Research 27:20-42.

652 Hart, K. M., P. Mooreside, and L. B. Crowder. 2006. Interpreting the spatio-temporal patterns of 653 sea turtle strandings: going with the flow. Biological Conservation 129:283-290. 
654 Higgins, B., A. Cannon, and G. Gitschlag. 1995. Sea turtle decomposition study. Unpublished report, National Marine Fisheries Service, Southeast Fisheries Science Center. Galveston, TX.

Hood, R. R., H. V. Wang, J. E. Purcell, E. D. Houde, and L. W. Harding. 1999. Modeling particles and pelagic organisms in Chesapeake Bay: Convergent features control plankton distributions. Journal of Geophysical Research 104:1223.

Hospital, A., J. A. Stronach, M. W. McCarthy, and M. Johncox. 2015. Spill response evaluation using an oil spill model. Aquatic Procedia 3:2-14.

662 Hsu, S. A., E. A. Meindl, and D. B. Gilhousen. 1994. Determining the power-law wind-profile exponent under near-neutral stability conditions at sea. Journal of Applied Meteorology 33:757-765.

Koch, V., H. Peckham, A. Mancini, and T. Eguchi. 2013. Estimating at-sea mortality of marine turtles from stranding frequencies and drifter experiments. PloS one 8:e56776.

Lett, C., P. Verley, C. Mullon, C. Parada, T. Brochier, P. Penven, and B. Blanke. 2008. A Lagrangian tool for modelling ichthyoplankton dynamics. Environmental Modelling \& Software 23:1210-1214.

Lutcavage, M., and J. A. Musick. 1985. Aspects of the biology of sea turtles in Virginia. Copeia 1985:449-456.

Mansfield, K. L. 2006. Sources of mortality, movements and behavior of sea turtles in Virginia. PhD Dissertation, Virginia Institute of Marine Science, College of William \& Mary. Gloucester Point, VA. 
675 Mansfield, K. L., V. S. Saba, J. A. Keinath, and J. A. Musick. 2009. Satellite tracking reveals a 676 dichotomy in migration strategies among juvenile loggerhead turtles in the Northwest Atlantic. Marine Biology 156:2555-2570.

678 Mesinger, F., G. DiMego, E. Kalnay, K. Mitchell, P. C. Shafran, W. Ebisuzaki, D. Jović, J. Woollen, E. Rogers, E. H. Berbery, M. B. Ek, Y. Fan, R. Grumbine, W. Higgins, H. Li, Y. Lin, G. Manikin, D. Parrish, W. Shi, F. Mesinger, G. DiMego, E. Kalnay, K. Mitchell, P. C. Shafran, W. Ebisuzaki, D. Jović, J. Woollen, E. Rogers, E. H. Berbery, M. B. Ek, Y. Fan, R. Grumbine, W. Higgins, H. Li, Y. Lin, G. Manikin, D. Parrish, and W. Shi. 2006. North American Regional Reanalysis. Bulletin of the American Meteorological

Micozzi, M. S. 1986. Experimental study of postmortem change under field conditions: effects Society 87:343-360. of freezing, thawing, and mechanical injury. Journal of forensic sciences 31:953-961.

690 Musick, J. A., and C. J. Limpus. 1997. Habitat utilization and migration in juvenile sea turtles. Pages 137-163 in P. L. Lutz and J. A. Musick, editors. The biology of sea turtles. CRC Press, Boca Rouge, FL.

693 National Marine Fisheries Service. 2006. Sea Turtle Conservation; Modification to Fishing 694 Activities. Federal Register 71:36024-36033. on Sea Turtle Conservation. National Academy Press, Washington, D.C:255. 
Nero, R. W., M. Cook, A. T. Coleman, M. Solangi, and R. Hardy. 2013. Using an ocean model to predict likely drift tracks of sea turtle carcasses in the north central Gulf of Mexico. Endangered Species Research 21:191-203.

Paraso, M. C., and A. Valle-Levinson. 1996. Meteorological Influences on Sea Level and Water Temperature in the Lower Chesapeake Bay: 1992. Estuaries 19:548-561.

Parker, J. R. O. 1970. Surfacing of dead fish following application of rotenone. Transactions of the American Fisheries Society 99:805-807.

Patterson, D. A., K. M. Skibo, D. P. Barnes, J. A. Hills, and J. S. Macdonald. 2007. The influence of water temperature on time to surface for adult sockeye salmon carcasses and the limitations in estimating salmon carcasses in the Fraser River , British Columbia. North American Journal of Fisheries Management 27:37-41.

Peltier, H., W. Dabin, P. Daniel, O. Van Canneyt, G. Dorémus, M. Huon, and V. Ridoux. 2012. The significance of stranding data as indicators of cetacean populations at sea: Modelling the drift of cetacean carcasses. Ecological Indicators 18:278-290.

Putman, N. F., and K. L. Mansfield. 2015. Direct Evidence of Swimming Demonstrates Active Dispersal in the Sea Turtle "Lost Years". Current Biology 25:1-7.

Reisdorf, A. G., R. Bux, D. Wyler, M. Benecke, C. Klug, M. W. Maisch, P. Fornaro, and A. Wetzel. 2012. Float, explode or sink: postmortem fate of lung-breathing marine vertebrates. Palaeobiodiversity and Palaeoenvironments 92:67-81.

Sis, R. F., and A. M. Landry. 1992. Postmortem Changes in the Turtle. Proceedings of the 23rd Annual International Association for Aquatic Animal Medicine, Hong Kong, pp. 17-19. San Leandro, CA. 
719 Swingle, W. M., M. C. Lynott, E. B. Bates, L. R. D’Eri, G. G. Lockhart, K. M. Phillips, and M.

720 D. Thomas. 2016. Virginia Sea Turtle and Marine Mammal Stranding Network 2015

721 Grant Report. Final Report to the Virginia Coastal Zone Management Program, NOAA

722 CZM Grant \#NA14NOS4190141, Task 49. VAQF Scientific Report 2016-01. Virginia

723 Beach, VA.

724 Terwilliger, K., and J.A. Musick (co-chairs), Virginia Sea Turtle and Marine Mammal

725 Conservation Team. 1995. Management Plan for Sea Turtles and Marine Mammals in

726 Virginia, Final Report to the National Oceanic and Atmospheric Administration. 56 pp.

727 Turtle Expert Working Group. 1998. An Assessment of the Kemp’s Ridley (Lepidochelys

728 kempii) and loggerhead (Caretta caretta) Sea Turtle Populations in the Western North

$729 \quad$ Atlantic. NOAA Technical Memorandum NMFS-SEFSC-409. 96 pp.

730 Wyneken, J. 2001. The anatomy of sea turtles. U.S. Department of Commerce, NOAA Technical

$731 \quad$ Memorandum NMFS-SEFSC 470. $172 \mathrm{pp}$. 


\section{Tables}

733 Table 1. Summary of condition code criteria. Descriptions are compiled from observations noted

734 during the sea turtle decomposition study and the National Oceanographic and Atmospheric

735 Administration's Sea Turtle Stranding Salvage Network stranding report forms and guidelines

736 (http://www.sefsc.noaa.gov/species/turtles/strandings.htm).

\begin{tabular}{|ccl|}
\hline $\begin{array}{c}\text { Condition } \\
\text { Code }\end{array}$ & Carcass State & \multicolumn{1}{c|}{ Criteria } \\
\hline 0 & $\begin{array}{c}\text { Alive } \\
\text { Fresh dead }\end{array}$ & $\begin{array}{l}\text { No odor, scutes and skin intact, no bloating, turtle may still be } \\
\text { in rigor } \\
\text { Mild to strong odor, slightly to very bloated, body mostly intact } \\
\text { with skin and scutes only beginning to peel, some small } \\
\text { cuts/scratches, internal organs still distinguishable } \\
\text { Carcass deflated, strong to no odor, moderate to significant } \\
\text { amount of skin peeling, internal organs beginning to liquefy, } \\
\text { hard to distinguish individual organs, large abrasions on body } \\
\text { cavity } \\
\text { Carapace and plastron no longer held together, any soft tissue } \\
\text { remains are minimal and unidentifiable, bones are clean or have } \\
\text { minimal attached tissues }\end{array}$ \\
\hline & Severely decomposed \\
\hline
\end{tabular}


738 Table 2. Summary of drifter measurements. Turtle curved carapace length (CCL) and straight

739 carapace length (SCL) measurements were taken from notch to tip. Asterisks $\left({ }^{*}\right)$ represents an

740 estimated measurement due to the presence of epibiota.

\begin{tabular}{|l|l|}
\hline \multicolumn{1}{|c|}{ Drifter type } & \multicolumn{1}{c|}{ Size (cm) } \\
\hline Bucket drifter & $\begin{array}{l}\text { Height: } 36.0 \\
\text { Diameter (bottom): 26.0 }\end{array}$ \\
\hline Wood-foam drifter & $\begin{array}{l}\text { CCL: } 88.5 \\
\text { SCL: 73.6 }\end{array}$ \\
\hline Turtle Carcass Drifter 1 & $\begin{array}{l}\text { CCL: } 83.5^{*} \\
\text { SCL: 76.7* }\end{array}$ \\
\hline Turtle Carcass Drifter 2 & CCL: $101.3^{*}$ \\
& SCL: 93.5 \\
\hline Turtle Carcass Drifter 3 & CCL: 72.5 \\
& SCL: 67.3 \\
\hline
\end{tabular}


742 Table 3. Summary of drift deployments. The duration of the trial was established based on

743 duration to slack tide, while the entire deployment was considered completed when the first

744 object beached.

\begin{tabular}{|c|c|c|c|c|}
\hline & Deployment 1 & Deployment 2 & Deployment 3 & Deployment 4 \\
\hline \multicolumn{5}{|c|}{ Composition } \\
\hline Number of Buckets & 2 & 2 & 2 & 2 \\
\hline $\begin{array}{l}\text { Number wood-foam } \\
\text { drifters }\end{array}$ & 2 & 2 & 2 & 2 \\
\hline Carcasses used & 1,2 & 3 & 3 & 3 \\
\hline \multicolumn{5}{|c|}{ Start of Deployment } \\
\hline Location & 37.17389, -76.2161 & 37.22833, -76.2161 & 37.22833, -76.1925 & 37.22232, -76.2328 \\
\hline Date & 13-Jun-16 & 24-Jun-16 & 1-Aug-16 & 15-Aug-16 \\
\hline Time (GMT) & $15: 41$ & $14: 15$ & $17: 00$ & $13: 29$ \\
\hline Water temperature $\left({ }^{\circ} \mathrm{C}\right)$ & 24.2 & 24.3 & 29.0 & 28.5 \\
\hline Air temperature $\left({ }^{\circ} \mathrm{C}\right)$ & 20.9 & 24.0 & 28.4 & 29.6 \\
\hline \multicolumn{5}{|c|}{ End of Trial } \\
\hline Date & 14-Jun-16 & 24-Jun-16 & 1-Aug-16 & 15-Aug-16 \\
\hline Time (GMT) & $00: 11$ & $19: 15$ & $19: 30$ & $18: 29$ \\
\hline Duration (hh:mm) & $8: 30$ & $5: 00$ & $2: 30$ & $5: 00$ \\
\hline $10 \mathrm{~m}$ wind speed $(\mathrm{m} / \mathrm{s})$ & $2.47 \pm 0.79$ & $2.37 \pm 0.45$ & $3.60 \pm 0.55$ & $2.73 \pm 0.82$ \\
\hline $\begin{array}{l}10 \mathrm{~m} \text { wind speed range } \\
(\mathrm{m} / \mathrm{s})\end{array}$ & $0.08-3.48$ & $1.35-3.56$ & $2.16-4.24$ & $1.32-3.95$ \\
\hline \multicolumn{5}{|c|}{ End of Deployment ${ }^{\mathrm{a}}$} \\
\hline Date & 15-Jun-16 & 25-Jun-16 & 2-Aug-16 & 18-Aug-16 \\
\hline Time (GMT) & $16: 30$ & $16: 50$ & $15: 13$ & $5: 22^{\mathrm{b}}$ \\
\hline Duration (hh:mm) & $48: 49$ & $26: 35$ & $22: 13$ & $63: 53$ \\
\hline $10 \mathrm{~m}$ average wind speed & $4.50 \pm 1.38$ & $3.67 \pm 1.77$ & $3.40 \pm 0.86$ & $3.76 \pm 1.17$ \\
\hline $\begin{array}{l}10 \mathrm{~m} \text { wind speed range } \\
(\mathrm{m} / \mathrm{s})\end{array}$ & $0.08-7.72$ & $0.01-7.52$ & $1.60-5.08$ & $1.32-6.40$ \\
\hline
\end{tabular}

a. Deployment considered completed once first item beached

746

b. One of the buckets stopping emitting location data on 16-Aug-16 at 1:29 GMT 
747 Table 4. Measurements of turtle carcasses used in the decomposition study.

\begin{tabular}{|c|c|c|c|c|c|c|c|c|}
\hline Measurement (cm) & Turtle 1 & Turtle 2 & Turtle 3 & Turtle 4 & Turtle 5 & Turtle 6 & Turtle 7 & Turtle 8 \\
\hline Species $^{\mathrm{a}}$ & $\mathrm{Cc}$ & Cc & $\mathrm{Cm}$ & $\mathrm{Lk}$ & $\mathrm{Cm}$ & $\mathrm{Cm}$ & $\mathrm{Cm}$ & Lk \\
\hline Weight (kg) & 31.5 & 36.5 & 3.036 & 2.378 & 3.464 & 2.74 & 2.50 & 6.38 \\
\hline $\begin{array}{l}\text { Straight carapace length } \\
\text { (notch to tip) }\end{array}$ & 68.0 & 67.2 & 29.3 & 26.3 & 30.4 & 28.6 & 28.9 & 37.4 \\
\hline Straight carapace width & 54.0 & 54.3 & 22.8 & 23.9 & 24.2 & 23.3 & 22.9 & 32.6 \\
\hline Maximum head length & 17.4 & 18.2 & 7.9 & 8.4 & 7.9 & 7.4 & 7.4 & 10.6 \\
\hline Body depth & 23.1 & 24.2 & 11.6 & 8.8 & 11.7 & 10.6 & 10.2 & 15.3 \\
\hline Straight plastron length & 46.5 & 52.6 & 25.7 & 20.2 & 24.9 & 23.6 & 23.3 & 27.8 \\
\hline $\begin{array}{l}\text { Circumference at max } \\
\text { width }\end{array}$ & 112.8 & 125.0 & 53.3 & 54.0 & 55.3 & 51.6 & 49.9 & 75.4 \\
\hline
\end{tabular}

a. $\mathrm{Cc}=$ Caretta caretta, $\mathrm{Cm}=$ Chelonia mydas, $\mathrm{Lk}=$ Lepidochelys kempii 
749 Table 5. Summary of decomposition results for each turtle carcass.

\begin{tabular}{|ccccrrrrrr|}
\hline $\begin{array}{c}\text { Turtle } \\
\text { No. }\end{array}$ & Species $^{\mathrm{a}}$ & \multicolumn{2}{c}{ Study Dates } & Temp $\left({ }^{\circ} \mathrm{C}\right)$ & \multicolumn{2}{c}{ Days } & \multicolumn{3}{c|}{ Minimum days to reach condition code } \\
& & Start & End & & buoyant & Code 1 & Code 2 & Code 3 & Code 5 \\
\hline 1 & Cc & 23-Jul-15 & 31-Jul-15 & $28.69 \pm 0.57$ & 3 & 0 & 2 & 4 & 6 \\
2 & Cc & 27-Aug-15 & 5-Sep-15 & $26.98 \pm 0.46$ & 5 & N/A $^{\mathrm{b}}$ & 0 & 3 & 5 \\
3 & Cm & 14-Jun-16 & 22-Jun-16 & $24.32 \pm 0.56$ & 5 & 0 & 2 & 4 & 7 \\
4 & Lk & 20-Jun-16 & 28-Jun-16 & $24.62 \pm 0.82$ & 4 & 0 & 2 & 5 & 7 \\
5 & Cm & 28-Jul-16 & 2-Aug-16 & $29.54 \pm 0.61$ & 2 & 0 & 1 & 3 & 4 \\
6 & Cm & 2-Aug-16 & 7-Aug-16 & $28.55 \pm 0.41$ & 2 & 0 & 1 & 3 & 5 \\
7 & Cm & 11-Oct-16 & 24-Oct-16 & $20.37 \pm 1.24$ & 8 & 0 & 2 & 6 & 12 \\
8 & Lk & 24-Oct-16 & 15-Nov-16 & $17.03 \pm 2.62$ & 15 & N/A $^{\mathrm{b}}$ & 0 & 9 & 18 \\
\hline
\end{tabular}

a. $\mathrm{Cc}=$ Caretta caretta, $\mathrm{Cm}=$ Chelonia mydas, $\mathrm{Lk}=$ Lepidochelys kempii

751 b. Turtles $2 \& 8$ began as an early code 2 
752 Table 6. Unconstrained (i.e., with a freely varying y-intercept) and constrained (i.e., y-

753 intercept=0) linear regression parameters, including the y-intercept (y-int.), slope, 95\%

754 confidence interval (C.I.), and significance (signif.), for the turtle carcass drifters and wood-foam

755 drifters during each deployment (deploy.). Slope and standard error are represented as a

756 percentage of wind speed. Level of significance of slope is represented by asterisks (. $<0.1$,

$757 *<0.05, * *<0.01, * * *<0.001)$.

\begin{tabular}{|c|c|c|c|c|c|c|c|}
\hline \multicolumn{8}{|c|}{ Along-wind component of leeway } \\
\hline \multirow[b]{2}{*}{ Drift object } & \multirow[b]{2}{*}{ Deploy. } & \multicolumn{4}{|c|}{ Unconstrained } & \multicolumn{2}{|c|}{ Constrained } \\
\hline & & Y-int. & $\begin{array}{c}\text { Slope } \\
\text { (\%) }\end{array}$ & 95\% C.I. (\%) & Signif. & $\begin{array}{l}\text { Slope } \\
\text { (\%) }\end{array}$ & 95\% C.I. (\%) \\
\hline Turtle carcass drifter 1 & 1 & -5.45 & 2.26 & $1.08-3.44$ & $* * *$ & 2.15 & $1.78-2.52$ \\
\hline Turtle carcass drifter 2 & 1 & 15.72 & 3.26 & $0.85-5.67$ & ** & 3.59 & $2.84-4.35$ \\
\hline \multirow[t]{3}{*}{ Turtle carcass drifter 3} & 2 & 5.41 & 1.32 & $(-0.73)-3.37$ & & 1.44 & $1.13-1.76$ \\
\hline & 3 & -103 & 2.76 & $0.98-4.54$ & * & 1.14 & $0.83-1.44$ \\
\hline & 4 & 10.71 & 1.05 & $(-0.625)-2.73$ & & 1.25 & $0.83-1.68$ \\
\hline \multirow[t]{4}{*}{ Wood-foam drifters } & 1 & -34.9 & 4.27 & 2.19-6.35 & $* * *$ & 3.54 & 2.19-6.35 \\
\hline & 2 & 2.94 & 0.66 & $(-1.23)-2.56$ & & 0.73 & $(-1.23)-2.55$ \\
\hline & 3 & -59.57 & 2.90 & $0.85-4.93$ & * & 1.95 & $0.85-4.93$ \\
\hline & 4 & 36.20 & 1.42 & $0.05-2.80$ & $*$ & 2.11 & $0.05-2.80$ \\
\hline \multicolumn{8}{|c|}{ Cross-wind component of leeway } \\
\hline & & \multicolumn{4}{|c|}{ Unconstrained } & \multicolumn{2}{|c|}{ Constrained } \\
\hline Drift object & & Y-int. & $\begin{array}{c}\text { Slope } \\
\text { (\%) }\end{array}$ & 95\% CI (\%) & Signif. & $\begin{array}{c}\text { Slope } \\
\text { (\%) }\end{array}$ & 95\% CI (\%) \\
\hline Turtle carcass drifter 1 & 1 & 22.53 & 1.09 & $(-2.31)-4.49$ & & 1.56 & $0.50-2.63$ \\
\hline Turtle carcass drifter 2 & 1 & -48.92 & 1.34 & $(-1.54)-4.22$ & & 0.31 & $(-0.60)-1.22$ \\
\hline \multirow[t]{3}{*}{ Turtle carcass drifter 3} & 2 & -20.34 & 0.89 & $(-3.25)-5.02$ & & 0.42 & $(-0.22)-1.05$ \\
\hline & 3 & -51.31 & 2.94 & $(-1.23)-1.82$ & & -0.52 & $(-0.72)-(-0.31)$ \\
\hline & 4 & -28.90 & 2.76 & $(-0.76)-1.32$ & & -0.27 & $(-0.54)-0.004$ \\
\hline \multirow[t]{4}{*}{ Wood-foam drifters } & 1 & -11.99 & 3.30 & $0.43-6.17$ & * & 3.05 & 2.14-3.95 \\
\hline & 2 & 171.09 & -3.40 & $(-5.47)-(-1.91)$ & $* * *$ & 0.25 & $(-0.12)-0.61$ \\
\hline & 3 & -76.18 & 1.13 & $(-3.71)-5.96$ & & -0.08 & $(-0.67)-0.52$ \\
\hline & 4 & -78.08 & 1.26 & $0.09-2.42$ & $*$ & -0.21 & $(-0.54)-0.12$ \\
\hline \multicolumn{8}{|c|}{ Leeway speed } \\
\hline & & \multicolumn{4}{|c|}{ Unconstrained } & \multicolumn{2}{|c|}{ Constrained } \\
\hline Drift object & & Y-int. & $\begin{array}{c}\text { Slope } \\
(\%)\end{array}$ & 95\% CI (\%) & Signif. & $\begin{array}{c}\text { Slope } \\
(\%)\end{array}$ & 95\% CI (\%) \\
\hline Turtle carcass c & 1 & 14.99 & 3.45 & $1.89-5.01$ & $* * *$ & 3.77 & $3.28-4.25$ \\
\hline Turtle carcass drifter 2 & 1 & 138.01 & 1.53 & $(-0.24)-3.30$ & & 4.43 & $3.76-5.09$ \\
\hline
\end{tabular}




\begin{tabular}{|lrrrrrrr|} 
Turtle carcass drifter 3 & 2 & 23.16 & 1.39 & $(-0.18)-2.96$ &. & 1.92 & $1.68-2.17$ \\
& 3 & -68.91 & 2.35 & $0.24-4.47$ & $*$ & 1.27 & $0.99-1.54$ \\
Wood-foam drifters & 4 & 16.90 & 1.14 & $(-0.28)-2.56$ & & 1.46 & $1.09-1.82$ \\
& 1 & 28.86 & 5.34 & $3.52-7.17$ & $* * *$ & 5.95 & $5.37-6.25$ \\
& 2 & 51.05 & 0.21 & $(-1.05)-1.46$ & & 1.38 & $1.17-1.59$ \\
& 3 & -32.28 & 2.66 & $0.59-4.72$ & $*$ & 2.15 & $1.89-2.40$ \\
& 4 & 52.25 & 1.38 & $0.15-2.61$ & $*$ & 2.37 & $2.03-2.70$ \\
\hline
\end{tabular}


759 Table 7. Mean distance $(\mathrm{km})$ of particle origin 2, 5, and 8 days prior to landing in stranding zone

760 under wind forcing conditions of $0 \%, 2 \%$, and $4 \%$. Results are compiled over 5 months of June

761 from the years 2001-2005.

\begin{tabular}{|c|rcc|rcc|rrr|}
\hline \multicolumn{10}{|c|}{ Mean distance from zone $(\mathrm{km})$} \\
\hline \multirow{2}{*}{ Zone \# } & \multicolumn{3}{|c|}{ 0\% wind } & \multicolumn{3}{c|}{ 2\% wind } & \multicolumn{3}{c|}{ 4\% wind } \\
\cline { 2 - 9 } & 2 days & 5 days & 8 days & 2 days & 5 days & 8 days & 2 days & 5 days & 8 days \\
\hline 1 & 9.78 & 21.80 & 33.77 & 12.14 & 18.34 & 23.36 & 14.35 & 19.12 & 22.35 \\
2 & 10.63 & 24.62 & 37.34 & 11.41 & 19.45 & 23.50 & 14.71 & 22.66 & 22.23 \\
3 & 9.47 & 17.82 & 26.95 & 12.86 & 19.36 & 22.79 & 17.05 & 21.87 & 24.33 \\
\hline
\end{tabular}

762 
764 Figure 1. (A) Location of study sites within the Chesapeake Bay, VA, including the

Figure 2. (A) Schematic of the decomposition study experimental design. (B) Image of a turtle stranding events in the remaining outlined zones.

decomposition rate study (triangle), release points for the four drifter deployments (circles), and target zones for the oceanographic simulations (black outline). The target zones represent county-level areas which make up 95.5\% of the reported 2001-2005 Virginia sea turtle strandings occurring within the model domain $(n=1487) .82 \%$ of these strandings ( $\mathrm{n}=1222$ ) occur specifically within three zones (shaded in dark gray and numbered). (B) Total number of stranding events per zone (gray) and events occurring during June only (white; 44\%, $\mathrm{n}=660$ ) from the years 2001-2005. Stranding zone number corresponds to locations in Figure 1A, while "other" is composed of documented stranding events in the remaining oulined zones.

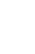

carcass floating at sea. (C) Image of a turtle carcass on shore.

Figure 3. (A) Turtle carcass, (B) bucket, and (C) wood-foam drifters.

Figure 4. (A) Duration of positive buoyancy (circles, solid line) and time to total decay

778
(triangles, dotted line) vs average water temperature $\left({ }^{\circ} \mathrm{C}\right)$. (B) Boxplot of the minimum number of days to reach each condition code stage.

Figure 5. Along-wind component of leeway $\left(10^{2} \mathrm{~m} / \mathrm{s}\right)$, cross-wind component of leeway $\left(10^{2}\right.$ $\mathrm{m} / \mathrm{s})$, and leeway speed vs. wind speed $\left(10^{2} \mathrm{~m} / \mathrm{s}\right)$ for each turtle carcass drifter and woodfoam deployment. Values are averaged over half hour periods. Solid lines represent the unconstrained linear regression mean and the shaded polygon represents the 95\% confidence intervals.

785 Figure 6. Complete drift tracks of all individual drifters during the four deployments. 
786 Figure 7. Relative particle density (\%) for probability of point of origin 2, 5 and 8 days prior to 787 stranding in Zone 1, as outlined in blue. Results include $0 \%, 2 \%$ and $4 \%$ of direct wind forcing on carcass drift. Simulation results are a composite over 5 months of June for the years 2001-2005.

790 Figure 8. Relative particle density (\%) for probability of point of origin 2, 5 and 8 days prior to stranding in outlined zone with $2 \%$ of direct wind forcing on carcass drift. Simulation results are a composite over 5 months of June for the years 2001-2005. 
794 Figure A1. Images of Turtle 1 at various condition code stages.

795 Figure A2. Schematic of sea turtle carcass drifter, including (A) carapace view, (B) plastron view, and (C) side-profile.

797 Figure A3. Self-righting buoy attachment with GPS for wood-foam and turtle carcass drifters.

798 Figure A4. NOAA National Weather Service daily weather map from July 24, 2016 depicting the presence of a weather front moving through the study site of deployment 2 (black box). Available from: http://www.wpc.ncep.noaa.gov/dailywxmap/index_20160624.html.

801 Figure A5. Locations of monitoring stations 8637611 York River East Rear Range Light (red circle), 8638614 Willoughby Degaussing Station (blue circle), and deployment 2 release location (yellow triangle).

804

Figure A6. Reported wind speed (m/s) and wind direction (degrees from true north) from monitoring stations 8637611 York River East Rear Range Light and 8638614 Willoughby Degaussing Station. Area between the blue lines represent the full time period of deployment 2.

808 Figure A7. Deployment 2 results of the along-wind component of leeway for turtle carcass drifter 3 using metrological data from monitoring stations (A) 8637611 York River East Rear Range Light and (B) 8638614 Willoughby Degaussing Station. Dashed lines

812 Figure A8. Relative number of particles from the oceanographic model making landfall over 813 elapsed time (days). Simulation results are a composite over 5 months of June from the $814 \quad$ years 2001-2005. 
815 Figure A9. Mean starting locations 2, 5, and 8 days prior to stranding in top zones. Simulation 816 results are a composite over 5 months of June from the years 2001-2005. 